\title{
A RANDOMIZED CONTROLLED TRIAL INVESTIGATING THE IMPACT OF INTERFERENTIAL THERAPY ON PAIN, RANGE OF MOTION AND QUALITY OF LIFE IN PATIENTS WITH CHRONIC NON-SPECIFIC LOW BACK PAIN
}

\author{
Sayed A. TANTAWY ${ }^{1,2 \unrhd}$, Dalia M. KAMEL ${ }^{1,3}$, Walid K. ABDELBASSET ${ }^{4,5}$, Gopal NAMBI ${ }^{5}$ \\ ${ }^{1}$ Department of Physiotherapy, College of Medical and Health Sciences, Ahlia University, Manama, \\ Kingdom of Bahrain \\ ${ }^{2}$ Department of Physiotherapy, Centre of Radiation Oncology and Nuclear Medicine, Cairo University, Egypt \\ ${ }^{3}$ Department of Physiotherapy for Women's Health, Faculty of Physical Therapy, Cairo University, Giza, Egypt \\ ${ }^{4}$ Department of Physical Therapy and Health Rehabilitation, College of Applied Medical Sciences, Prince \\ Sattam Bin Abdul Aziz University, Alkharj, Saudi Arabia \\ ${ }^{5}$ Department of Physical Therapy, Kasr Al-Aini Hospital, Cairo University, Giza, Egypt
}

Received 02 Jan 2020, Accepted 09 Febr 2020

https://doi.org/10.31688/ABMU.2020.55.1.05

\begin{abstract}
Introduction. Electrotherapy is a non-pharmacologic, non-invasive and simple method of back pain treatment that is also applied using interferential (IF) therapy.

The objective of the study was to investigate the effect of IF on pain, range of motion, and quality of life in patients with chronic non-specific low back pain (CNLBP).

Materials and methods. 61 patients suffering from CNLBP were randomly assigned to IF group $(n=30)$ and placebo IF $(n=31)$. All patients received supervised exercises 3 times per week for 4 weeks. The outcome measures were visual analogue scale (VAS), lumbar range of motion (ROM) in terms of flexion\& extension and the Short Form-36 (SF-36) health questionnaire to evaluate the quality of life (QOL).
\end{abstract}

\section{Résumé}

Un essai contrôlé aléatoire analysant l'impact de la thérapie interférentielle sur la douleur, la régularité du mouvement et la qualité de vie chez les patients atteints d'une douleur lombaire chronique non spécifique

Introduction. L'électrothérapie est une méthode non pharmacologique, non invasive et simple de traitement des douleurs dorsales qui est aussi appliquée par thérapie interférentielle (IF).

L'objectif de l'étude était d'étudier l'effet de la FI sur la douleur, l'amplitude des mouvements et la qualité de vie chez les patients souffrant de lombalgie chronique non spécifique (CNLBP).

Matériel et méthodes. 61 patients souffrant de CNLBP ont été randomisés dans le groupe IF $(\mathrm{n}=30)$ et le placebo IF $(n=31)$. Tous les patients ont bénéficié 
Results. There were no significant differences between groups in terms of baseline and demographic characteristics $(p>0.05)$. There were significant differences between pre and post intervention in IF group in all measured parameters (VAS at rest, VAS during activity, flexion, extension range of motion and QOL in term of physical and mental components) $(\mathrm{p}<0.05)$, while there were nonsignificant difference in all measured outcome in placebo group except the quality of life and flexion range of motion which showed statistical significant difference. When comparing the 2 groups, the results revealed that there were highly significant differences in all measured parameters in favor of IF group.

Conclusions. The study revealed that 4 weeks of IF treatment combined with exercise therapy is significantly effective in reducing pain, improving lumbar ROM and QOL in patients with CNLBP.

Keywords: low back pain, mechanical low back pain, range of motion, interferential therapy, quality of life.

\author{
Abbreviations list: \\ CNSLBP - Chronic non-specific low back pain \\ LBP - Low back pain \\ IF - Interferential \\ TENS - Transcutaneous electrical stimulation \\ VAS - Visual analogue scale \\ ROM - Range of motion \\ QOL - Quality of life
}

\section{INTRODUCTION}

Chronic non-specific low back pain (CNSLBP) is defined as mechanical low back pain (LBP) lasting more than 3 months ${ }^{1}$. It is considered the second most common health problem after headache ${ }^{2}$, with an estimated prevalence of $31 \%$ in the general population ${ }^{3}$. It is reported that CNSLBP represents about $85 \%$ of overall $\mathrm{LBP}^{4}$. LBP is the most common cause of years lived with disability in both developed and developing countries, and sixth in overall disease burden $^{5,6}$. LBP affects the quality of life, reduces productivity at work place through increasing sick leaves ${ }^{7}$, and it is associated with high risk of depression, regardless of gender ${ }^{8}$, especially in patients between 40 to 80 years old $\%$. In despite of the fact that the course of LBP has a good prognosis, $5-10 \%$ of the patients continue to have perpetual symptoms?

$41 \%$ of the patients with CNSLBP recover after one year ${ }^{10}$. There are different methods of physiotherapy for low back pain management and improvement d'exercices supervisés 3 fois par semaine pendant 4 semaines. Les mesures des résultats étaient l'échelle visuelle analogue (EVA), l'amplitude des mouvements lombaires (ROM) en termes de flexion et d'extension et le questionnaire de santé Short Form-36 (SF-36) pour évaluer la qualité de vie (QOL).

Résultats. Il n'y avait pas de différences significatives entre les groupes en termes de caractéristique de base et démographique ( $p>0,05)$. Il y avait des différences significatives entre pré et post intervention dans le groupe IF dans tous les paramètres mesurés (EVA au repos, EVA pendant l'activité, Flexion, amplitude de mouvement d'extension et $\mathrm{QV}$ en termes de composantes physique et mentale) ( $\mathrm{p}<0,05)$, tandis qu'il y avait de différence non significative dans tous les résultats mesurés dans le groupe placebo, à l'exception de la qualité de vie et de l'amplitude de flexion des mouvements qui ont montré une différence statistiquement significative. En comparant les 2 groupes, les résultats ont révélé qu'il y avait des différences très significatives dans tous les paramètres mesurés en faveur du groupe IF.

Conclusions. L'étude a révélé que quatre semaines de traitement IF associées à une thérapie par l'exercice sont significativement efficaces pour réduire la douleur, améliorer la ROM lombaire et la qualité de vie chez les patients atteints de CNLBP.

Mots-clés: lombalgie, lombalgie mécanique, amplitude de mouvement, thérapie interférentielle, qualité de vie.

of functional disabilities, as therapeutic exercise, lumbar mobilization, and manipulation ${ }^{11,12}$.

Electrotherapy is a non-pharmaceutical and non-invasive method for pain reduction, which includes transcutaneous electrical stimulation (TENS), laser photobiomodulation, ultrasound, magnetic therapy and interferential current ${ }^{13-17}$.

Interferential therapy (IF) is a medium frequency alternating current, with amplitude-modulation at a low frequency ${ }^{18}$. It has been reported to decrease pain, to enhance circulation ${ }^{1}$ and to act as a counter-irritant effect ${ }^{19}$. It is used effectively because its penetration in the skin is deep, with minor discomfort ${ }^{18}$.

There are two explanations for pain reduction by electrotherapy: the release of endogenous opioids ${ }^{20}$ and the gate control theory ${ }^{21}$.

However, the clinical effect of interferential currents on LBP remains controversial ${ }^{22}$.

The objective of the Study was to investigate the effect of IF in patients with CNSLBP. 


\section{Materials AND Methods}

The study was approved by the Research Ethical Committee (P.T. REC/ 012/001811) of the Faculty of Physical Therapy, Cairo University, Egypt. The clinical trial was registered at Clinicaltrial.gov with identifying number NCT03961477.

\section{Participants}

The study was conducted in outpatient clinics in Cairo University Hospitals. 61 patients (30 men and 31 women) were invited to participate in the study. Subjects aged between 25 and 60 years were included in the study if they had LBP for at least three months. Patients with spinal pathology (tumor, nerve root compression, fracture, and compromise), cardiopulmonary conditions, pregnancy, and who received physiotherapy in the last eight weeks or any contraindications to the use of electrotherapy were excluded. All the patients signed the informed consent.

\section{Randomization}

From 72 patients, 61 patients met the inclusion criteria and represented the group of study. Seven patients did not meet the inclusion criteria, and 4 subjects refused to participate in the study. Participants were randomly assigned to the IF group $(n=30)$ or placebo group $(n=31)$. By asking the subjects to draw an envelope from a concealed box, each envelope contains a yellow or blue card and they were accordingly assigned to the two groups of the study. The individuals who drew yellow cards were assigned to the IF group, and those who drew blue cards were included in the placebo group, as presented in Fig. 1.

\section{Assessment measures}

The assessment measures included visual analogue scale (VAS), lumbar range of motion (LROM) in terms of flexion and extension, and the short form-36 (SF-36) questionnaire to evaluate the quality of life (QOL).

The severity of pain was evaluated using a VAS. The participants were requested to put a line on the scale, perpendicularly, that matched to their pain intensity. VAS scores represent the pain intensity as none, mild, moderate, or severe. The accompanying cut-off was used for the pain scale: $0.4 \mathrm{~mm}$, no pain; 5. $44 \mathrm{~mm}$, mild pain; $45.74 \mathrm{~mm}$, moderate pain; and $75-100 \mathrm{~mm}$, severe pain ${ }^{23}$.

LROM was measured by using a modified Schober test to assess both flexion and extension. The Short Form-36 (SF-36) is valid, reliable, and has been demonstrated in many international studies ${ }^{24-26}$. It is used to assess the QOL through eight domains, which depend on physical and emotional aspects.
The eight domains include the following: physical functioning, role imitations owing to physical health or emotional problems, energy/fatigue, emotional well-being, social functioning, pain, and general health. Furthermore, a single item is included to identify any health changes, making the short-form, a helpful index for QOL change over time. The physical and mental summary scores are determined by calculating the mean of the physical and mental scores related items ${ }^{26-28}$.

\section{Procedure}

The demographic data (age, weight, height) of the participants were recorded at the first visit for the treatment. Each subject in both groups was positioned in prone lying and the area to be treated was exposed. The IF group, which included 30 subjects, received IF (Sonopuls 692, Enraf-Nonius BV, Rotterdam, The Netherlands) in the quadripolar technique. Four self-adhesive electrodes $(10 \times 12 \mathrm{~cm}$, and $75 \mathrm{~cm}^{2}$ in area) were applied using a crossed technique in the area between $L_{1}$ and $L_{5}$ vertebrae and a rectangular stimulus $1 / 1$ was used. The IF parameters were a carrier frequency of $4000 \mathrm{~Hz}$, at constant voltage and amplitude modulation of $80 \mathrm{~Hz}$ for 30 minutes for 4 weeks. The IF current was increased gradually, according to the subject's condition, with comfortable tingling sensation. For the placebo group, which included 31 subjects, the parameters were as in the IF group, but with no current.

\section{Exercise Therapy}

All the participants in both groups performed a supervised exercises program based on the literature $^{29,30}, 5$ times per week for 4 weeks. The exercise program consisted of bridging exercises, posterior pelvic tilt and active strengthening exercises for the abdominal, back, muscles. The duration of each session was 20 minutes for mobilization and $15-20$ repetitions for each muscle group.

Posterior pelvic tilt

Position of the patient: supine lying position with flexed knees and flat feet on the bed. The patients were instructed to tighten the abdominal muscles and make the pelvis tilted backwards, and then to make the lower back flat against the bed.

\section{Bridging exercise}

Position of the patient: supine lying position with flexed knees and flat feet on the bed and arms by the side. The patient was instructed to lift the pelvis and lower back and hold for 5 seconds, to return to original position and relax. 


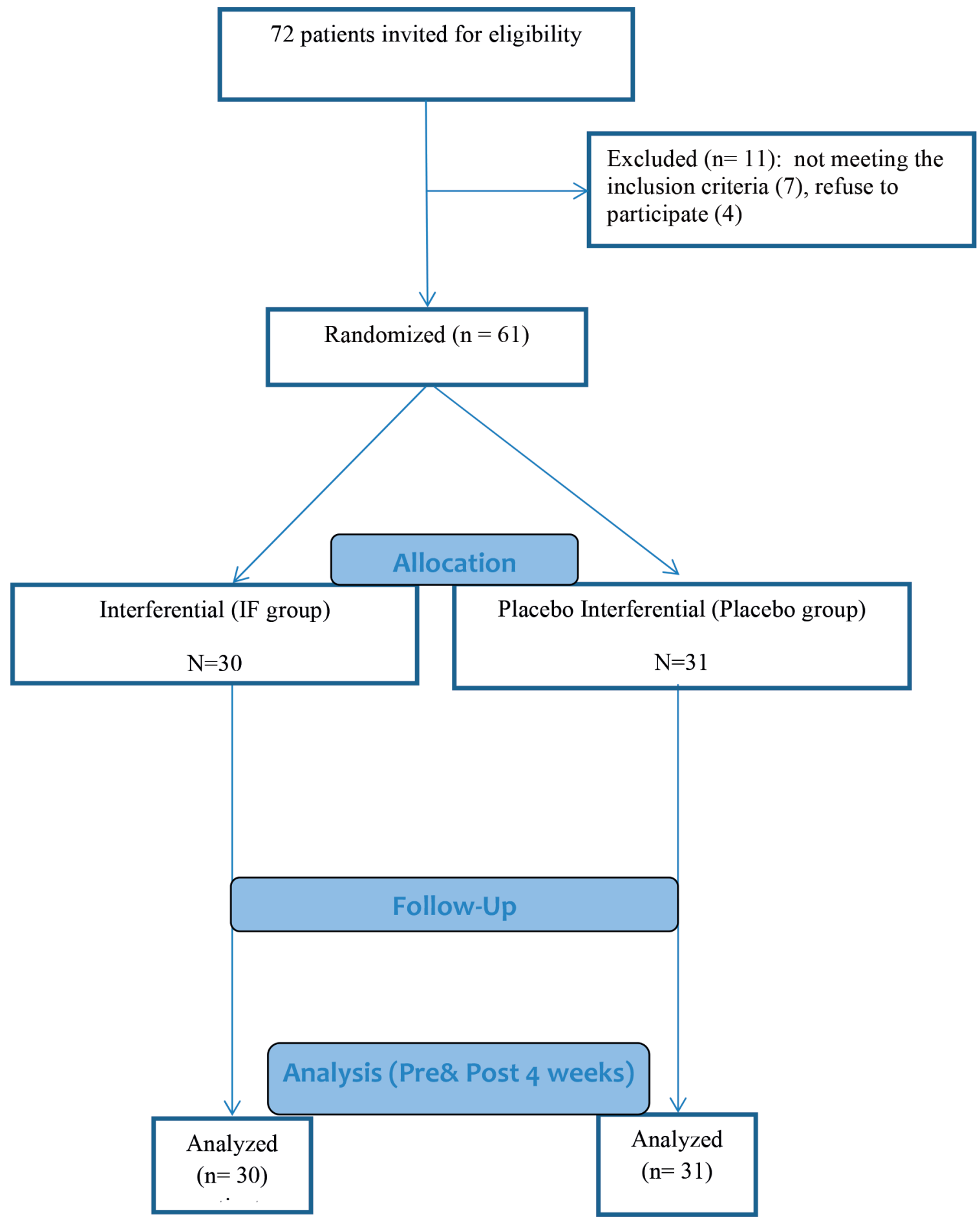

Fig. 1 Study flow chart

Sample Size

The sample size was estimated using a main measure of VAS score. A pilot study, which included 7 patients with nonspecific low back pain who underwent similar treatment for the same period, revealed a significant mean difference of VAS score (6.9 and 5.7), with standard deviation of (1.6). Unpaired t-test, power of $80 \%$ and $\alpha=0.05$ required a sample of 56 patients for this study (28 in each group). The study recruited 72 patients to consider the dropout rates of $20 \%$.

\section{Statistical analysis}

Descriptive analysis was calculated in the form of means and standard deviations. Paired t-test was utilized to measure changes within group. Inferential 
statistics measured alterations of all parameters using unpaired t-test between IF and placebo groups. Furthermore, Chi square was used to test some demographic characteristics of both groups. SPSS version 23.0 (SPSS, Chicago, IL, USA) was used for data analysis, with a significance level of $p<0.05$ for all statistical measurements.

\section{RESULTS}

61 patients participated in this study and were randomized into two groups (IF and placebo). The IF group $(n=30)$ included patients with an average age of 34.6 years, $80 \%$ women, and 4.12 years mean duration of LBP symptoms. The placebo group $(n=31)$ included patients with an average age of 34.46 years, $83.9 \%$ women, and 3.82 years mean duration of LBP symptoms. There were no significant differences between groups in terms of baseline and demographic characteristics $(\mathrm{p}>0.05)$, as presented in Table 1.

Regarding the VAS at rest, IF group showed an average decrease by 3.5 points, while the placebo group showed only a 0.3 point decrease. Same observation was noted in VAS at activity, with 2.7 and 0.7 points decrease for IF and placebo groups, respectively. The back-flexion ROM was significantly increased in IF and placebo groups, with an average increase of $54.7^{\circ}$ and $47.2^{\circ}$ post-treatment, in comparison to $39.4^{\circ}$ and $40.9^{\circ}$ pre-treatment, respectively (Table 2 ).

There were significant differences between pre and post intervention in IF group in all measured parameters (VAS at rest, VAS during activity, flexion, extension range of motion and QOL in term of physical and mental components) $(\mathrm{p}<0.05)$.

Intergroup comparison revealed that patients in the placebo group demonstrated improvement in the VAS at rest, VAS during activity, flexion and extension range of motion, but not statistically significant. Furthermore, statistically significant differences were showed in flexion ROM and the patient's QOL, including the physical and mental components QOL $(\mathrm{p}<0.05)$, as presented in Table 2.

The post-intervention comparison between the IF and placebo groups demonstrated statistic significant differences in all parameters outcomes in favor of IF group $(\mathrm{p}<0.05)$ (Table 2$)$.

\section{Discussion}

The current study investigated the efficacy of IF therapy in the treatment of CNSLBP. The results revealed a significant improvement of all the measured parameters in favor of IF group. This improvement was in terms of decreased pain of the VAS, increased back ROM and QoL.

Table 1. Demographic data for both groups

\begin{tabular}{cccc}
\hline Parameters & IF group & Sham group & P-value \\
\hline Age & $34.6 \pm 6.91$ & $34.46 \pm 6.9$ & 0.95 \\
\hline Gender n. $(\mathrm{M} / \mathrm{F})$ & $6(20 \%) / 24(80 \%)$ & $5(16.1 \%) / 26(83.9 \%)$ & 0.87 \\
\hline Weight $(\mathrm{kg})$ & $72.45 \pm 15.18$ & $69.87 \pm 11.76$ & 0.46 \\
\hline Height $(\mathrm{m})$ & $1.67 \pm 0.05$ & $1.65 \pm 0.04$ & 0.09 \\
\hline BMI $\left(\mathrm{Kg} / \mathrm{m}^{2}\right)$ & $26.7 \pm 5.8$ & $26.8 \pm 5.7$ & 0.9 \\
\hline Duration of symptoms (years) & $4.12 \pm 1.9$ & $3.82 \pm 2.3$ & 0.58 \\
\hline \multicolumn{2}{c}{ Occupations $(\%)$} & 0.92 \\
\hline Employee & $15(50 \%)$ & $16(51.6 \%)$ & 0.89 \\
\hline Housewife & $7(23.3 \%)$ & $8(25.8 \%)$ & 0.91 \\
\hline Worker & $8(26.7 \%)$ & $7(22.6 \%)$ & \\
\hline
\end{tabular}

Significant at $\mathrm{p}$ value $<0.05$; the data are presented as means \pm standard deviations.

Table 2. Statistical analysis of all parameters before and after intervention in IF and placebo If groups

\begin{tabular}{|c|c|c|c|c|c|c|c|c|c|c|c|c|c|c|c|c|c|c|}
\hline \multirow[t]{2}{*}{ variables } & \multicolumn{3}{|c|}{ VAS at rest } & \multicolumn{3}{|c|}{ VAS at activity } & \multicolumn{3}{|c|}{ Flexion ROM (mm) } & \multicolumn{3}{|c|}{ Extension ROM (mm) } & \multicolumn{3}{|c|}{ SF-36T M PCS score } & \multicolumn{3}{|c|}{ SF-36TM MCS score } \\
\hline & Pre & Post & value & Pre & Post & P-value & Pre & Post & P-value & Pre & Post & P-value & Pre & Post & P-value & Pre & Post & P-value \\
\hline IF $g$ & $\begin{array}{c}6.9 \\
(1.9)\end{array}$ & $\begin{array}{c}3.4 \\
(1.16)\end{array}$ & 0. & $\begin{array}{c}5.1 \\
(2.9)\end{array}$ & $\begin{array}{c}2.4 \\
(0.37)\end{array}$ & 0.0001 & $\begin{array}{c}39.4 \\
(11.8)\end{array}$ & $\begin{array}{c}54.7 \\
(10.7)\end{array}$ & 0.0 & $\begin{array}{l}16.7 \\
(6.5)\end{array}$ & $\begin{array}{c}25.9 \\
(5.03)\end{array}$ & 01 & $\begin{array}{l}43.7 \\
(1.2)\end{array}$ & $\begin{array}{c}49.1 \\
(3.10)\end{array}$ & 01 & $\begin{array}{l}45.8 \\
(1.33)\end{array}$ & $\begin{array}{c}50.1 \\
(2.25)\end{array}$ & 01 \\
\hline Placebo IF & $\begin{array}{c}6.6 \\
(2.1)\end{array}$ & $\begin{array}{c}6.3 \\
(2.4)\end{array}$ & 0.60 & $\begin{array}{c}5.3 \\
(3.4)\end{array}$ & $\begin{array}{c}4.6 \\
(3.3)\end{array}$ & 0.41 & $\begin{array}{c}40.9 \\
(12.7)\end{array}$ & $\begin{array}{c}47.2 \\
(12.5)\end{array}$ & 0.05 & $\begin{array}{l}17.2 \\
(6.8)\end{array}$ & $\begin{array}{l}20.3 \\
(7.6)\end{array}$ & 0.09 & $\begin{array}{c}44.2 \\
(1.28)\end{array}$ & $\begin{array}{c}47.4 \\
(3)\end{array}$ & 0.0001 & $\begin{array}{c}46.1 \\
(2.07)\end{array}$ & $\begin{array}{c}48.3 \\
(2.16)\end{array}$ & 0.0001 \\
\hline P-value & 0.6 & 0.0001 & & 0.8 & 0.001 & & 0.6 & 0.01 & & 0.8 & 0.05 & & 0.12 & 0.03 & & 0.5 & 0.001 & \\
\hline
\end{tabular}

Significant at $\mathrm{p}$ value $<0.05$; the data are presented as means \pm standard deviations; VAS: visual analogue scale; Rom: range of motion; mm: millimeters; PCS: Physical Component Summary of the SF-36TM questionnaire; MCS: Mental Component Summary of the SF-36TM questionnaire; If: Interferential group. 
LBP is the one of the main causes of absenteeism from work. Most of the subjects affected are aged between 25-60 years, and the subjects likely to be disabled have the age between $50-60$ years $^{31}$. In the current study, the participants have a similar age, as their ages ranged between $20-60$ years, with about $48 \%$ over 50 years old.

In the current study, the analgesic effects of IF on the VAS were explained as the IF effects might be similar to transcutaneous electrical nerve stimulation (TENS) ${ }^{32,33}$. Furthermore, there are two possibilities to explain pain reduction; the release of endogenous opioids ${ }^{20}$ and the gate control theor $y^{21}$. IF stimulation penetrates deeper into the tissues, leading to significant and long-term pain reduction, and functional ability improvement on both subjective and objective parameters ${ }^{34}$. This is consistent with the current study for VAS at rest and at activity, which in turn reflected on the increased back ROM.

We performed a comparison between the IF group and a placebo group. The placebo group did not show a significant decrease on VAS. The literature supported the same observation, as IF was better in pain modulation ${ }^{35,36}$.

The effect of IF on LBP in the literature is controversial, as some studies reported beneficial therapeutic and positive effects of the $\mathrm{IF}^{34,37,38}$, which is in support to the results of the present study. In addition, Lara-Palomo et a ${ }^{39}$ concluded that the use of IF electro-massage provides a significant improvement in QOL and pain reduction compared to superficial massage. Nevertheless, chronic pain impairs the general health related $\mathrm{QOL}^{40}$. Furthermore, Fuentes et $\mathrm{al}^{41}$ applied one IF session and showed a significant pain reduction in patients with nonspecific CLBP compared to placebo.

On the other hand, other studies reported no significant differences between IF and lumbar traction $^{42}$, Pilates and placebo ${ }^{43}$, in terms of improvement of disability and pain in LBP patients. This may be attributed to the QOL improvement that was noted in the placebo group. Also, a systematic review showed that IF is superior only when it is a combined intervention ${ }^{44}$. This is in line to the result of IF combined with therapeutic exercises in the current study.

A supervised exercise program was introduced to the study groups. Its effect was prominent in augmented effects of IF group and the quality of life (physical and emotional) results of the placebo group. This can be attributed to the mild ${ }^{45}$ to significant ${ }^{46}$ effects of exercises in reducing pain and improving functions in patients with chronic low back pain ${ }^{47}$.

Limitations of the study: the outcomes were only measured after four weeks of interventions and the patients were not followed up after the end of the treatment. Furthermore, the sample size needs to be greater, for more validation of the results.

\section{Conclusions}

Based on the study results, subjects with CNLBP can be treated with IF. IF is considered as an effective method to reduce pain, improve spinal range of motion in terms of flexion and extension, and improve the patients' quality of life.

\section{Author contributions}

Conceptualization, S.T. and D.K.; methodology, S.T.; software, W.A.; validation, W.A. and G.N.; formal analysis, D.K.; investigation, G.N.; resources, W.A. and S.T.; data curation, D.K. and G.N.; writing - original draft preparation, S.T. and W.A.; writing - review and editing, W.A., G.N. and S.T.; visualization, D.K., and W.A.; supervision, S.T. and D.K..; project administration, S.T. All the authors have read and agreed with the final version of the article.

\section{Compliance with Ethics Requirements:}

„The authors declare no conflict of interest regarding this article"

"The authors declare that all the procedures and experiments of this study respect the ethical standards in the Helsinki Declaration of 1975, as revised in 2008(5), as well as the national law. Informed consent was obtained from all the patients included in the study"

"No funding for this study"

\section{Acknowledgments: none}

\section{References}

1. Airaksinen O, Brox JI, Cedraschi C, et al. Chapter 4: European guidelines for the management of chronic nonspecific low back pain. Eur Spine J 2006; 15 Suppl 2:S192-300.

2. Krismer M, van Tulder M. Strategies for prevention and management of musculoskeletal conditions: low back pain (non-specific). Best Pract Res Clin Rheumatol 2007;21(1):77-91.

3. Hoy D, Bain C, Williams G, March L, et al. A systematic review of the global prevalence of low back pain. Arthritis Rheum 2012; 64:2028-37.

4. Langevin HM, Sherman KJ. Patho- physiological model for chronic low back pain integrating connective tissue and nervous system mechanisms. Med Hypotheses 2007; 68:74-80.

5. Hoy D, March L, Brooks P, et al. The global burden of low back pain: estimates from the Global Burden of Disease 2010 study. Ann Rheum Dis 2014; 73: 968-74.

6. Global Burden of Disease Study Collaborators. Global, regional, and national incidence, prevalence, and years lived with disability for 301 acute and chronic diseases and injuries in 188 countries, 1990-2013: a systematic analysis for 
the Global Burden of Disease Study 2013. Lancet 2015; 386: 743-800.

7. Dunn KM, Croft PR. Epidemiology and natural history of low back pain. Eura Medico Phys 2004; 40:9-13.

8. Lopez-Lopez D, Vilar-Fernandez JM, Calvo-Lobo C, et al. Evaluation of depression in subacute low back pain: a case control study. Pain Physician. 2017;20(4):E499-E505.

9. Calvo-Lobo C, Vilar Fernández JM, Becerro-de-Bengoa-Vallejo R, et al. Relationship of depression in participants with nonspecific acute or subacute low back pain and no-pain by age distribution.J Pain Res. 2017;10:129-135.

10. Costa Lda C, Maher CG, McAuley JH, et al. Prognosis for patients with chronic low back pain: inception cohort study. BMJ 2009; 339: b3829.

11. Hayden JA1, van Tulder MW, Malmivaara AV, et al. Meta-analysis: exercise therapy for nonspecific low back pain. Ann Intern Med 2005; 142(9): 765-775.

12. Kamel DM, Abdel Raoof NA, Tantawy SA. Efficacy of lumbar mobilization on postpartum low back pain in Egyptian females: A randomized control trial. J Back Musculoskelet Rehabil 2016; 29(1):55-63.

13. Tantawy SA, Kamel DM, Abdelbasset WK. Does transcutaneous electrical nerve stimulation reduce pain and improve quality of life in patients with idiopathic chronic orchialgia? A randomized controlled trial. Journal of Pain Research 2018;11:77-82.

14. Tantawy SA, Abdelbasset WK, Kamel DM, et al. Laser photobiomodulation is more effective than ultrasound therapy in patients with chronic nonspecific low back pain: a comparative study. Lasers Med Sci. 2018 Oct 17. doi: 10.1007/ s10103-018-2665-8.

15. Kamel DM, Hamed NS, Abdel Raoof NA, et al. Pulsed magnetic field versus ultrasound in the treatment of postnatal carpal tunnel syndrome: A randomized controlled trial in the women of an Egyptian population. J Adv Res. 2017; 8(1): 45-53.

16. Palmer S, Martin D. Interferential current for pain control. In: Kitchen S (ed.) Electrotherapy evidence-based practice, eleventh edition. Edinburgh: Churchill Livingstone. 2002; 287-98.

17. Elgohary HMI, Tantawy SA, Eladl HM. Impact of Interferential current on pain relief among patients with orchialgia. Int J Physiother. 2016;3(4):450-454.

18. Franco YR, Liebano RE, Moura KF, et al. Efficacy of the addition of interferential current to Pilates method in patients with low back pain: A protocol of a randomized controlled trial. BMC Musculoskelet Disord 2014;15: 420.

19. Poitras S, Brosseau L. Evidence-informed management of chronic low back pain with transcutaneous electrical nerve stimulation, interferential current, electrical muscle stimulation, ultrasound, and thermotherapy. Spine. 2008; 8: 226-33.

20. Beatti A, Tucker K, Chipchase L. A double-blind placebo-controlled investigation into the effects of interferential therapy on experimentally induced pain using a cross-over design. Int Musculoskelet Med. 2012;34:8.

21. Johnson MI, Tabasam G. A single-blind placebo-controlled investigation into the analgesic effects of interferential currents on experimentally induced ischemic pain in healthy subjects. Clin Physiol Funct Imaging. 2002; 22:187-96.

22. Facci LM, Nowotny JP, Tormem F, et al. Effects of transcutaneous electrical nerve stimulation (TENS) and interferential currents (IFC) in patients with nonspecific chronic low back pain: Randomized clinical trial. Sao Paulo Med J. 2011;129: 206-216.
23. Jensen MP, Chen C, Brugger AM. Interpretation of visual analog scale ratings and change scores: a reanalysis of two clinical trials of postoperative pain. J Pain. 2003;4:407-414.

24. Clayson DJ, Wild DJ, Quarterman P, et al. A comparative review of health-related quality-of-life measures for use in HIV/ AIDS clinical trials. Pharmacoeconomics. 2006;24(8):751-765.

25. Haywood KL, Garratt AM, Fitzpatrick R. Quality of life in older people: a structured review of generic self-assessed health instruments. Qual Life Res. 2005;14(7):1651-1668.

26. McHorney CA, Ware JE Jr, Lu JF, Sherbourne CD. The MOS 36-item Short-Form Health Survey (SF-36): III. Tests of data quality, scaling assumptions and reliability across diverse patient groups. Med Care. 1994; 32(1):40-66.

27. Leone MA, Beghi E, Righini C, Apolone G, et al. Epilepsy and quality of life in adults: a review of instruments. Epilepsy Res. 2005; 66(1-3): 23-44.

28. Neelakantan D, Omojole F, Clark TJ, et al. Quality of life instruments in studies of chronic pelvic pain: a systematic review. J Obstet Gynaecol. 2004; 24(8):851-858.

29. Grönblad M, Hupli M, Wennerstrand $P$, et al. Intercorrelation and test-retest reliability of the Pain Disability Index (PDI) and the Oswestry Disability Questionnaire (ODQ) and their correlation with pain intensity in low back pain patients. Clin J Pain. 1993; 9(3): 189-195.

30. Olawale OA, Agudzeamegah CM. The efficacy of interferential therapy and exercise therapy in the treatment of low back pain. Niger J Exp Clin Biosci. 2014; 2:10-4.

31. Corbin CB, Lindsey R, Welk G. Concepts of Fitness and Wellness. 4th ed. New York: McGraw-Hill; 2002.

32. Cheing GL, Hui-Chan CW. Analgesic effects of transcutaneous electrical nerve stimulation and interferential currents on heat pain in healthy subjects. J Rehabil Med. 2003; 35 : 15-19.

33. Albornoz-Cabello M. Estimulación eléctrica transcutánea y neuromuscular. Barcelona: Elsevier, 2010.

34. Rajfur J, Pasternok M, Rajfur K, et al. Efficacy of selected electrical therapies on chronic low back pain: a comparative clinical pilot study. Med Sci Monit. 2017;23:85-100.

35. Young SL, Woodburg MG, Fryday-Field K. Efficacy of interferential current stimulation alone for pain reduction in patients with osteoarthritis of the knee: a randomized placebo control clinical trial. Phys Ther. 1991;71:S52.

36. Johnson MI, Tabasam GA. Placebo controlled investigation into the analgesic effects of interferential currents (IFC) on induced ischemic pain in healthy subjects. Proceedings of Pain Society of Great Britain Annual Conference 1999; 9.

37. Corrêa JB, Costa LO, de Oliveira NT, et al. Effects of the carrier frequency of interferential current on pain modulation in patients with chronic nonspecific low back pain: a protocol of a randomised controlled trial. BMC Musculoskelet Disord. 2013;27(14):195.

38. Dohnert MB, Bauer JP, Pavão TS. Study of the effectiveness of interferential current as compared to transcutaneous electrical nerve stimulation in reducing chronic low back pain. Rev Dor. São Paulo. 2015; 16(1):27-31.

39. Lara-Palomo IC, Aguilar-Ferrándiz ME, Matarán-Peñarrocha GA, et al. Short-term effects of interferential current electro-massage in adults with chronic non-specific low back pain: A randomized controlled trial. Clin Rehabil. 2013; 27:439-49.

40- Palomo-López P, Calvo-Lobo C, Becerro-de-Bengoa-Vallejo $\mathrm{R}$, et al. Quality of life related to foot health status in women with fibromyalgia: a case-control study. Arch Med Sci. 2019; 15 (3): 694-699. 
41. Fuentes J, Armijo-Olivo S, Funabashi M, et al. Enhanced therapeutic alliance modulates pain intensity and muscle pain sensitivity in patients with chronic low back pain: an experimental controlled study. Phys Ther. 2014; 94:477-89.

42. Werners R, Pynsent PB, Bulstrode CJK. Randomized trial comparing interferential therapy with motorized lumbar traction and massage in the management of low back pain in a primary care setting. Spine. 1999; 24: 1579-83.

43. Franco KM, Franco YD, Oliveira NB, et al. Is interferential current before Pilates exercises more effective than placebo in patients with chronic nonspecific low back pain? A randomized controlled trial. Arch Phys Med Rehabil. 2017; 98(2):320-328
44. Fuentes JP, Armijo Olivo S, Magee DJ, et al. Effectiveness of interferential current therapy in the management of musculoskeletal pain: a systematic review and meta-analysis. Phys Ther. 2010; 90: 1219-38.

45. Hayden JA, van Tulder MW, Malmivaara A, et al. Exercise therapy for treatment of non-specific low back pain. Cochrane Database Syst Rev. 2005;(3):CD000335.

46. Rok S, Wytrazek M, Bilski B. Efficacy of therapeutic exercises in low back pain surveyed in a group of nurses. Med Pr. 2005; 56:235-9.

47. Tiglis M, Neagu TP, Elfara M, et al. Nefopam and its role in modulating acute and chronic pain. Rev Chim (Bucharest). 2018;69(10):2877-2880. 